\title{
PREVENÇÃO DO TERRORISMO INTERNACIONAL - UMA CONTEXTUALIZAÇÃO HISTÓRICA
}

\author{
Marcelo Carreiro ${ }^{1}$
}

\section{Resumo}

Além da resposta meramente militar e o discurso triunfalista pontual, o combate ao terrorismo internacional é antigo tema do direito internacional público, o que esboça um esforço global continuado para a solução do tema - esforço este que, embora não tenha sido inaugurado pelos eventos de setembro de 2001, certamente ganhou fôlego com a partir daí, com a projeção política do tema. $\mathrm{O}$ artigo em tela analisa o histórico dos tratados referentes ao combate ao terrorismo, delineia seu caráter intrinsecamente global e aponta seus desdobramentos, como o respeito aos direitos humanos e o controle das armas de destruição em massa.

Palavras-Chave: Terrorismo. Direito internacional público. História das relações internacionais.

\section{Abstract}

Besides the purely military response and the occasional triumphalist discourse, the fight against international terrorism is an old is-

1 Bacharel em História (UFRJ), Mestre em História Comparada (Programa Pró-Defesa em Relações Internacionais, Segurança e Defesa Nacionais-PPGHC/UFRJ) e Doutorando em História Comparada (PPGHC/UFRJ). 
80 | InterAção

sue of public international law, which outlines an ongoing global effort to resolve the issue - an effort that, while has not been opened by the events of September 2001, certainly picked up steam in from there, with the political projection of the theme. This article examines the history of the treaties concerning the combating of terrorism, outlines their global character and points its developments, such as the respect for human rights and the control of weapons of mass destruction.

Keywords: Terrorism. Public international law. History of the international relations.

\section{INTRODUÇÃO}

Ao completarmos a trágica efeméride de uma década completa dos atentados de 11 de setembro de 2001, temos a distância histórica para analisarmos as alterações estruturais nas relações internacionais levadas a cabo para o combate ao terrorismo internacional.

Quando dos atentados, tornou-se lugar-comum no imaginário estadunidense o slogan de que os ataques terroristas "mudaram tudo”. Esse discurso inflamado visava calcar uma mudança de paradigma nas políticas norte-americanas, internas e externas, inaugurando um novo contexto da História, sem compromisso com o passado ao qual fora desconectado de forma tão abrupta e violenta.

Usado ad nauseam pela imprensa ${ }^{2}$, logo o discurso do "tudo

2 E.g. WALSH, Mary. Urban Pain, From Sea to Sea. The New York Times. Nova lorque, 30 de Setembro de 2001. Disponível na Internet no endereço http://query.nytimes. 
InterAção | 81

mudou" foi entronizado pelas falas oficiais do executivo ${ }^{3}$, tornando-se a visão oficial dos atentados, que garantiam a liberdade do governo para reestruturar sua agenda de segurança interna e de política externa a partir de seu contexto neoconservador.

Sem dúvida, os atentados de 9/11 são um marco de inflexão da história dos EUA em suas relações externas, que tenderam desde então ao unilateralismo e ao esvaziamento dos fóruns multilaterais - especialmente no tocante à segurança internacional e ao combate contra o novo terrorismo globalizado jihadista.

No entanto, o direito internacional público possui uma longa tradição no combate ao terrorismo, datada desde o início do terrorismo nacionalista de âmbito internacional inaugurado na década de 1970, quando surge o "terrorista playboy", abarrotado de financiamento através de ações "expropriatórias" ou garantidas através do patrocínio por um Estado simpatizante, sendo então possíveis ações estonteantemente performáticas, como sequestros de políticos/embaixadores ou de aviões comerciais (algo que se inicia já em 1931) ${ }^{4}$.

Atos de terrorismo são combatidos pelo direito internacional público desde 1963, quando é elaborada em Tóquio a primeira convenção sobre o assunto, a Convenção Relativa às Infrações e a Certos Outros Atos Cometidos a Bordo de Aeronaves. No documento,

com/gst/fullpage.html?res=9802E7D9163DF933A0575AC0A9679C8B63, acessado em $1^{\circ}$ de fevereiro de 2012.

3 E.g.: CHENEY, Richard. Discurso "Remarks by the Vice President" na McChord Air Force Base, Tacoma, Washington em 22 de Dezembro de 2003. Disponível na Internet no endereço http://www.usembassy.it/viewer/article.asp?article=/file2003_12/alia/ a3122306.htm, acessado em $1^{\circ}$ de fevereiro de 2012.

4 LAQUEUR, Walter. A History of Terrorism. New Jersey: Transaction Publishers., 2001. 5 Disponível na Internet no endereço http://untreaty.un.org/English/Terrorism/Conv1. 
que entrou em vigor em 1969, a palavra terrorismo é ausente - mas tipificam-se as ameaças de um voo (contra a defesa nacional, contra a aeronave, contra os passageiros, contra os bens transportados), além de combater potenciais perigos à ordem e disciplina de bordo estabelecendo a autoridade do comandante da aeronave em situações de risco.

$\mathrm{Na}$ verdade, a Convenção trata do estatuto legal dos voos e suas jurisdições, no contexto de aumento das viagens internacionais aéreas. Sequestros de aeronaves ainda eram raros, passando a ocorrer sistematicamente apenas no decorrer ao início da década de 1970.

É nesse período que uma série ações terroristas consecutivas teriam lugar: em 21 de fevereiro o atentado da Frente Popular para a Libertação da Palestina (PFLP) contra o voo 330 da Swissair em Zurique, matando 38 passageiros; em 31 de março o sequestro do voo 351 da Japan Airlines realizado pelo Exército Vermelho Japonês; em 6 de setembro o sequestro simultâneo de quatro aeronaves (TWA 741, Swissair 100, El Al 219, PanAm 93), evento conhecido como os "sequestros de Dawson Field"; em 7 de setembro o sequestro do voo 775 da British Overseas Airways Corporation, pela PFLP, complementando os sequestros do dia anterior.

Nesse cenário de súbita insegurança internacional, tem lugar em Haia, em dezembro de 1970, a Convenção para a Repressão ao Apoderamento Ilícito de Aeronaves (ou Convenção de Aeronaves) ${ }^{6}$, que entra em vigor em 1973. No documento, é tratado o caráter in-

pdf, acessado em $1^{\circ}$ de fevereiro de 2012.

6 Disponível na Internet no endereço http://untreaty.un.org/English/Terrorism/Conv2. pdf, acessado em $1^{\circ}$ de fevereiro de 2012. 
InterAção | 83

ternacional do crime - ainda que não se fale em terrorismo. A ideia é visivelmente evitar a normatização do termo, combatendo-se suas ações práticas e evitando-se o debate sobre a tipificação do método - a árdua definição precisa da categoria "terrorismo" se torna menos importante do que efetivamente combatê-lo.

Esse cuidado no uso do termo será revisto logo em 1971 pela OEA, que promulga em fevereiro a Convenção para Prevenir e Punir Atos de Terrorismo Configurados na Forma de Delitos Contra as Pessoas e a Extorsão Conexa, Quando Tiverem Eles Transcendência Internacional (ou Convenção da Tomada Ilegal) ${ }^{7}$. Na convenção, aparece pela primeira vez a palavra terrorismo, citado da seguinte forma em seu preâmbulo: "A Assembleia Geral da Organização, na Resolução 4, de Junho de 1970, fortemente condena os atos de terrorismo, especificamente o sequestro de pessoas e as extorsões em conexão com esses crimes, que são declarados como sérios crimes comuns".

Tipificado dessa forma, apenas referente a sequestros, o terrorismo é tratado explicitamente como crime comum, cuja natureza internacional o tratado tenta jurisdicionar - assim como a colaboração internacional no caso de sequestros e extradições de terroristas.

O combate ao terrorismo internacional e suas ações aéreas é desenvolvido pela ONU em 1971, através da Convenção para a Repressão de Atos Ilicitos Contra a Segurança da Aviação Civil (ou Convenção da Aviação Civil) ${ }^{8}$, organizada pela Organização Internacio-

7 Disponível na Internet no endereço http://www.oas.org/juridico/english/ treaties/a-49.html , acessado em $1^{\circ}$ de fevereiro de 2012.

8 Disponível na Internet no endereço http://untreaty.un.org/English/Terrorism/Conv3. pdf , acessado em $1^{\circ}$ de fevereiro de 2012. 
nal de Aviação Civil (ICAO) em Montreal. A Convenção, que entra em vigor em 1975, torna crime a violência contra passageiros - caso ameace a aeronave. Também criminaliza a cumplicidade e a intenção do crime, além de especificar como ilegal o transporte de explosivos.

A convenção conclama a "punição severa" dos crimes que ela prevê, na tentativa de combate ao nascente terrorismo nacionalista internacional - mas não sugere penas.

Com tais medidas internacionais, o terrorismo deixa de lado os atentados aéreos - e passa a focar suas ações em embaixadas e corpos diplomáticos. Em setembro de 1972, imediatamente após o Massacre de Munique, a organização Setembro Negro envia uma carta-bomba à embaixada israelense em Londres, assassinando um diplomata. Em março de 1973, sequestram cinco diplomatas sauditas da embaixada em Cartum, no Sudão - três diplomatas ocidentais são assassinados. Em 14 de Dezembro, o Consulado Algeriano em Marselha é bombardeado pela organização anti-árabe Grupo Charles Martel, assassinando quatro pessoas e ferindo outras vinte. No mesmo dia, respondendo a esses atentados, a Assembleia Geral da ONU adota a Convenção sobre a Prevenção e Punição de Crimes Contra Pessoas que Gozam de Proteção Internacional, Inclusive os Agentes Diplomáticos (ou a Convenção dos Agentes Diplomáticos) ${ }^{9}$, que entra em vigor em 1977.

$\mathrm{Na}$ nova Convenção, são definidas as pessoas que gozam de proteção internacional (chefe de Estado, Ministro do Exterior, representante ou oficial de organização internacional - e seus familia-

9 Disponível na Internet no endereço http://untreaty.un.org/English/Terrorism/Conv4. pdf , acessado em $1^{\circ}$ de fevereiro de 2012. 
InterAção | 85

res). Além disso, requer aos signatários que criminalizem e tornem puníveis atos contra essas pessoas, seus bens, meios de transporte e acomodações.

Como resposta, mais uma vez o terrorismo troca de alvo: em março de 1978, membros da organização indonésia República da Moluca do Sul (RMS), em luta armada por sua independência da Holanda, ocupam o prédio da administração da província de Assen, mantendo mais de 67 reféns e assassinando um policial. Em novembro de 1979, cerca de 1500 manifestantes sunitas ocupam a Grande Mesquita de Meca, tomando o governo saudita de surpresa. A ocupação durou duas semanas, teve o nebuloso envolvimento de paraquedistas franceses e teve como resultado 225 mortos e 556 feridos entre os terroristas e peregrinos - e 127 mortes e 451 feridos entre os militares. A “Tomada da Grande Mesquita”, como ficou conhecido o evento, teve efeito devastador no cenário internacional, além de influenciar o recrudescimento do governo saudita em sua aplicação do direito islâmico, fechando o regime ${ }^{10}$.

$O$ resultado da comunidade internacional a esses eventos foi a adoção da Convenção Internacional Contra a Tomada de Reféns (ou Convenção dos Reféns) ${ }^{11}$, de Dezembro de 1973. O acordo, que entrou em vigor apenas em 1983, criminaliza não apenas o uso de reféns, a detenção, mas também as ameaças de morte e injúrias como atos de pressão política contra Estados, organizações internacionais

10 WRIGHT, Lawrence. 0 Vulto das Duas Torres - A Al-Qaeda e o Caminho até 0 11/9. São Paulo: Ed. Companhia das Letras, 2006. Pg. 105-109.

11 Disponível na Internet no endereço http://untreaty.un.org/English/Terrorism/ Conv5.pdf, acessado em $1^{\circ}$ de fevereiro de 2012. 
86 | InterAção

intergovernamentais, pessoas físicas ou jurídicas, ou mesmo grupo de pessoas.

Pouco depois, em outubro 1979, tem lugar em Viena a Convenção Sobre a Proteção Física de Materiais Nucleares (ou Convenção para Materiais Nucleares) ${ }^{12}$, no contexto do final da deténte da Guerra Fria. O acordo, que entra em vigor em 1987, criminaliza a possessão ilegal de material nuclear, assim como seu uso, transferência ou roubo - deixando, portanto, as potências nucleares como detentoras únicas dos materiais físseis disponíveis. $\mathrm{O}$ tratado, no entanto, vai além do estabelecimento do oligopólio nuclear e criminaliza o uso ou ameaça de uso de material nuclear para morte, injúria ou dano substancial à propriedade - portanto, seu uso em um ato terrorista.

A convenção é, assim, o primeiro passo na prevenção do terrorismo nuclear - tema que ganha vulto no mundo pós 9/11 e após Guerra do Iraque como pior método de ação terrorista, alimentando uma insegurança pública que, por vezes, beira a histeria. Voltaremos ao terrorismo nuclear a seguir, mas é significativo que seu combate internacional efetivo comece em 1979 - e não no contexto antiterrorista do $9 / 11$.

Tolhido pela crescente legislação internacional sobre suas práticas, o terrorismo internacional passa a visar ainda um outro alvo - aeroportos. Em dezembro de 1975, o aeroporto nova-iorquino de La Guardia é atingido por uma bomba - onze pessoas morrem e setenta e cinco ficam feridas. Em maio de 1981 é a vez do JFK, tam-

12 Disponível na Internet no endereço http://untreaty.un.org/English/Terrorism/ Conv6.pdf, acessado em $1^{\circ}$ de fevereiro de 2012. 
bém em Nova Iorque, sofrer um atentado à bomba, onde é assassinada uma pessoa. Em 1982 é a vez do aeroporto de Ancara, na Turquia - nove pessoas são mortas e setenta feridas. Em 1983 o aeroporto de Orly também sofre um atentado, morrendo oito pessoas e deixando mais de 50 feridas. Em 1985, no aeroporto de Tóquio, uma bomba explode no carregamento de um avião, matando dois bagageiros. Em dezembro do mesmo ano os aeroportos de Roma (Da Vinci, 16 mortes e 99 feridos) e Viena (Schwechat, dois mortos e 39 feridos) são atacados simultaneamente.

Sete atentados em menos de dez anos, com um total de quarenta e nove mortos e trezentos e três feridos, acabam por pressionar a comunidade internacional, que em 1988 apresenta o Protocolo para a Repressão de Atos Ilícitos de Violência em Aeroportos Que Prestem Serviço à Aviação Civil Internacional, Complementar à Convenção para a Repressão de Atos Ilícitos contra a Segurança da Aviação Civil (ou Protocolo dos Aeroportos) $)^{13}$. O acordo, que entra em vigor em 1990, estende de forma perspicaz as deliberações da Convenção de 1971, que deliberava sobre a aeronave e seus passageiros, aos aeroportos e seus transeuntes.

O mesmo princípio de proteção de transportes internacionais é aplicado às embarcações marítimas, através da Convenção para a Supressão de Atos Ilegais Contra a Segurança da Navegação Marítima (ou Convenção Marítima) ${ }^{14}$, de 1988. A convenção combate ações

13 Disponível na Internet no endereço http://untreaty.un.org/English/Terrorism/ Conv7.pdf, acessado em $1^{\circ}$ de fevereiro de 2012.

14 Disponível na Internet no endereço http://untreaty.un.org/English/Terrorism/ Conv8.pdf, acessado em $1^{\circ}$ de fevereiro de 2012. 
88 | InterAção

terroristas no mar, como o sequestro do cruzeiro Achille Lauro pela Força de Libertação da Palestina (PLF), em Outubro de 1985.

Da mesma forma, também em 1988 é estabelecido o Protocolo de Repressão a Atos Ilegais Contra a Segurança de Plataformas Fixas Continentais (ou Protocolo das PlataformasFixas) ${ }^{15}$, que expande as mesmas proteções e garantias às plataformas marítimas, entrando em vigor em 1992.

Seguindo com a mesma proposta de combate às ações terroristas, ainda sem nomear ou definir o termo terrorismo nas convenções e protocolos, a ONU é impulsionada pelo atentado ao voo 103 da Pan Am a procurar uma solução mais ampla para o de safio do terrorismo internacional. No atentado, em Dezembro de 1988, a aeronave foi destruída por terroristas líbios sobre Lockerbie, a Escócia, matando 270 passageiros, sendo o maior atentado terrorista até então à vidas americanas - e o maior número de mortes em tempos de paz no Reino Unido ${ }^{16}$.

Com o ataque, a ONU apresenta em 1991 a Convenção para a Marcação de Explosivos Plásticos para Fins de Deteç̧ão (ou Convenção de Explosivos Plásticos) ${ }^{17}$, que designa o controle e o limite internacional do uso de explosivos plásticos - arma principal do terrorismo até então. Pela primeira vez as palavras terrorismo e terror são usadas numa convenção internacional da ONU, embora sem uma definição

15 Disponível na Internet no endereço http://untreaty.un.org/English/Terrorism/ Conv9.pdf, acessado em $1^{\circ}$ de fevereiro de 2012.

16 Special Report: Lockerbie. The Guardian, reportagem especial disponível na Internet no endereço http://www.guardian.co.uk/Lockerbie, acessado em $1^{\circ}$ de fevereiro de 2012. 17 Disponível na Internet no endereço http://untreaty.un.org/English/Terrorism/ Conv10.pdf, acessado em $1^{\circ}$ de fevereiro de 2012. 
InterAção | 89

precisa - a estratégia continua sendo o cerceamento das ações terroristas, evitando-se o debate sobre a definição do termo terrorismo.

Essas determinações serão completadas em 1997 pela Convenção Internacional Sobre a Supressão de Atentados Terroristas com Bombas (ou Convenção sobre Atentados à Bomba) ${ }^{18}$. O acordo, que vigora a partir de 2001, cria um regime de jurisdição universal sobre o uso e intenção de uso de explosivos em lugares públicos, visando causar danos pessoais ou a destruição de propriedades.

É nesse contexto legal que se surge o terrorismo global contemporâneo, nos atentados da Al-Qaeda às embaixadas americanas no Quênia e na Tanzânia em 1998, onde são assassinadas 225 pessoas e feridas mais de 4.000. Após a investigação do FBI e a descoberta de uma ampla rede de financiamento e simpatizantes internacionais do novo terrorismo, a ONU apresenta em Dezembro de 1999 a Convenção Internacional para a Supressão de Financiamento do Terrorismo (ou Convenção Sobre o Financiamento Terrorista) ${ }^{19}$.

No documento, os signatários se comprometem a prevenir e combater o financiamento direto e indireto de organizações terroristas e grupos ligados ao tráfico de drogas e de armas. Para isso, prevê o congelamento de bens e a expropriação de fundos alocados em atividades terroristas, alegando que o sigilo bancário não é mais justificação adequada para a ausência de cooperação na área.

Delineia-se um quadro de combate multilateral sistemático

18 Disponível na Internet no endereço http://www2.mre.gov.br/dai/TerrorBombas. $\mathrm{htm}$, acessado em $1^{\circ}$ de fevereiro de 2012.

19 Disponível na Internet no endereço http://www2.mre.gov.br/dai/m_5.640_2005. htm, acessado em $1^{\circ}$ de fevereiro de 2012. 
90 | InterAção

das atividades terroristas, que teve início com o combate ao sequestro de aeronaves, seguido pelo de pessoal diplomático, passando ao combate à tomada de reféns e a proteção de aeroportos, navios e plataformas - até o controle de explosivos, o combate às bombas terroristas e, finalmente, chega à atividade raiz de suporte do terrorismo: seu financiamento, mesmo quando encoberto por sigilo bancário.

Nessa realidade de constante perda de terreno da atividade terrorista é que tem lugar o espetacular ataque de 9/11, que emprega mais uma vez táticas novas ao usar um sequestro de avião não como uma arma política - mas uma arma militar, tornando a aeronave um míssil contra alvos fixos em terra. Com sua estrutura descentralizada, que chega a levantar dúvidas da aplicabilidade do termo organiza$c_{\tilde{a} 0^{20}}$, a Al-Qaeda apresenta uma nova realidade ao combate internacional do terrorismo - que será continuado apesar da relutância norte-americana em confiar seu tema principal de segurança nacional à um debate multilateral.

A realidade de um novo terrorismo global e pulverizado numa rede ${ }^{21}$ é um tema inerentemente multilateral, dado seu alcance universal resultado de sua estrutura não-territorial. Mesmo a hiperpotência pouco pode fazer sozinha em seu ataque unilateral naïve às bases do terrorismo - campos de treinamento não são fontes de financiamento, nem centros de propaganda. O terrorismo, como es-

20 CURTIS, Adam. The Power of Nightmares - The Rise of Politics of Fear. BBC, 2004. 21 Que, mesmo se existente, é de tal volatilidade que desafia a definição do termo, assemelhando-se mais a células independentes guiadas por diretrizes gerais emanadas de um centro que atua mais como um guia do que como uma cadeia de comando efetiva. 
InterAção | 91

tratégia de ação, não possui fortaleza central para ser sitiada - e essa sua "aterritorialidade" é exacerbada com o modelo pulverizado e em rede da Al-Qaeda.

Imediatamente após os atentados de 2001, a OEA promulga sua Convenção Interamericana Contra o Terrorismo ${ }^{22}$, que reconhece todas as Convenções anteriores e estreita a colaboração do sistema interamericano no combate ao terrorismo. Além disso, o acordo elimina justificativas de asilo político à extradição de terroristas e se compromete integralmente com os Direitos Humanos conforme a Carta da ONU e da OEA, além dos demais acordos, convenções e tratados sobre o tema.

O próximo passo global no combate ao terrorismo acontece em Setembro de 2005, com a Convenção para a Supressão de Atos de Terrorismo Nuclear (ou Convenção para Terrorismo Nuclear) ${ }^{23}$. O documento discorre sobre atentados contra instalações nucleares - e não sobre o uso de armamentos nucleares em atividades terroristas, como seu título pode dar a entender. Nesse enfoque, estabelece a cooperação em casos de crise e pós-crise, inclusive prevendo o emprego a Agência Internacional Atômica (IAEA).

Finalmente, em setembro de 2006 a ONU promulga a $E s-$ tratégia Contra-Terrorista Global ${ }^{24}$ apresentada como resolução da

22 Disponível na Internet no endereço http://www.oas.org/juridico/english/ treaties/a-66.html, acessado em $1^{\circ}$ de fevereiro de 2012.

23 Disponível na Internet no endereço http://untreaty.un.org/English/Terrorism/English_18_15.pdf, acessado em $1^{\circ}$ de fevereiro de 2012.

24 Disponível na Internet no endereço http://unbisnet.un.org:8080/ipac20/ ipac.jsp?session $=11982904$ TSX52.2002\&menu $=$ search\&aspect=power\&npp $=50 \& i p p=20 \& s p p=20 \&$ profile $=$ bibga\& $r i=1 \&$ source $=\% 7 E \% 21$ horizon\&index $=$. 
92 I InterAção

Assembleia Geral (A/RES/60/288). A origem do documento reside numa proposta do Secretário-Geral no encontro de setembro de 2005. Nessa proposta, são delineados cinco pilares de ação para o terrorismo - a dissuasão para grupos não recorrerem ao terrorismo; negar os meios de terroristas conduzirem seus ataques; negar a Estados os meios de financiar grupos terroristas; desenvolver as capacidades estatais de contenção do terrorismo; defender os Direitos Humanos no contexto do terrorismo e contraterrorismo.

Posteriormente aceita na Conferência de setembro de 2005, e com os pilares de ação desenvolvidos pelo Secretário-Geral, a proposta foi finalmente aceita em uníssono pela Assembleia Geral, cujos membros começaram em maio de 2006 a realizar consultas sobre o desenvolvimento de formas futuras de cooperação global nas ações contra terroristas. É interessante a semântica - as medidas propostas como base de desenvolvimento do contraterrorismo possuem caráter explicitamente defensivo. Medidas ofensivas, denominadas de antiterrorismo, não são contempladas pelas discussões ${ }^{25}$.

A proposta é ousada: estabelecer uma Força Tarefa de Implementação do Contraterrorismo, composta multidisciplinarmente por membros da ONU oriundos de diversos escritórios ativos na proposta, tais como a Agência Internacional de Energia Atômica, a Organização Mundial de Saúde, Organização Civil Internacional, o

UD\&term $=a \% 2 F r e s \% 2 F 60 \% 2 F \quad 288 \& \mathrm{x}=0 \& \mathrm{y}=0 \&$ aspect=power, acessado em $1^{\circ}$ de fevereiro de 2012.

25 Sobre as diferenças entre contra terrorismo e anti terrorismo ver PINHEIRO, Gen. Bda. Álvaro de Souza. 0 Antiterrorismo e o Contraterrorismo. Portal Defesa@Net, Março de 2004. Disponível na Internet no endereço http://www.defesanet.com.br/noticia/ terrorismo.htm, acessado em $1^{\circ}$ de fevereiro de 2012. 
InterAção | 93

Fundo Monetário Internacional, o Banco Mundial, a Organização Marítima Internacional, dentre vários outros, na tentativa de prover um framework de trabalho para ações preventivas de caráter global, regional, sub-regional e local (estatal) contra atos terroristas - sempre com atenção explícita e clara de defesa dos Direitos Humanos no processo de combate ao terrorismo ${ }^{26}$.

É compreensível esperarmos resultados desse gigantesco trabalho conjunto de colaboração nos próximos anos. Auspiciosa já foi a unanimidade inédita da Assembleia Geral na condenação do terrorismo, quando da aprovação da resolução 60/288, em 2005, expressa em seu parágrafo 81 da seguinte forma:

"We strongly condemn terrorism in all its forms and manifestations, committed by whomever, wherever and for whatever purposes, as it constitutes one of the most serious threats to international peace and security. ${ }^{27}$

É possível afirmar, finalmente, que o $9 / 11$ de fato mudou tudo - sem ele, não teríamos o nível de parceria atual no combate ao terrorismo, agora visto como fenômeno global e uma das ameaças do processo inconcluso (e polissêmico) da globalização. Portanto, dependendo exclusivamente da ação conjunta dos Estados através da cooperação internacional através dos mecanismos multilaterais (essencialmente a ONU), na criação de uma legislação internacio-

26 Factsheet disponível na Internet no endereço http://www.un.org/terrorism/pdfs/ CT_factsheet_may2007x.pdf, acessado em $1^{\circ}$ de fevereiro de 2012.

27 Texto final do encontro, disponível na Internet no endereço http://www.un.org/terrorism/strategy/worldsummit-outcome.html, acessado em $1^{\circ}$ de fevereiro de 2012. 
94 | InterAção

nal que proteja cidadãos, garanta os princípios estabelecidos dos Direitos Humanos e previna o terrorismo em sua nova modalidade histórica.

Trabalho claramente além das capacidades possíveis para um único Estado e suas noções neo-realistas de política - mesmo que esse Estado se apresente como a única superpotência atual.

Nesse esforço conjunto da comunidade internacional, é marcante a participação brasileira ao ratificarmos prontamente todas as convenções - com a curiosa exceção apenas da Convenção Marítima de 1988, referente à proteção da navegação marítima, e seu protocolo adicional sobre as plataformas continentais. Chama a atenção essa ausência brasileira especialmente pela rationale atual da Marinha brasileira, que justifica sua expansão como proteção à prospecção crescente de petróleo na costa brasileira, na área chamada pelo marketing militar de "Amazônia Azul". ${ }^{28}$

Se a Marinha, conforme seu discurso, busca proteger o pré-sal de agressões externas promovidas por terroristas ${ }^{29}$, deveria começar por recomendar a assinatura da convenção de 1988 e seu protocolo adicional, adequando plenamente a posição brasileira com o combate internacional ao terrorismo.

28 Vidigal, Armando Amorim Ferreira et al. Amazônia Azul: 0 Mar que nos Pertence. Rio de Janeiro: Record, 2006. Pág. 258.

29 De MARTINI, Fernando. Área do Pré-Sal Terá Patrulha da Marinha. In Poder Naval, 25 de agosto de 2008. Disponível na Internet no endereço http://www.naval.com.br/ blog/2008/08/25/area-do-pre-sal-tera-patrulha-da-marinha/\#axzz1uySvf8tN, acessado em $1^{\circ}$ de fevereiro de 2012. 


\section{Listagem dos Tratados Internacionais de Prevenção ao Terrorismo Inter- nacional, Com a Participação Brasileira}

\begin{tabular}{|l|l|l|l|}
\hline \multicolumn{1}{|c|}{ Convenção / Protocolo } & $\begin{array}{c}\text { Data de } \\
\text { Apresentação }\end{array}$ & $\begin{array}{c}\text { Data da } \\
\text { Entrada em } \\
\text { Vigor }\end{array}$ & $\begin{array}{c}\text { Ratificação pelo } \\
\text { Brasil }\end{array}$ \\
\hline $\begin{array}{l}\text { Convention on Offences } \\
\text { and Certain Other Acts } \\
\text { Committed Onboard Aircraft }\end{array}$ & $\begin{array}{l}\text { Setembro de } \\
1963\end{array}$ & $\begin{array}{l}\text { Dezembro de } \\
1969\end{array}$ & $\begin{array}{l}\text { Abril de 1970 } \\
\text { (Decreto 66520) }\end{array}$ \\
\hline $\begin{array}{l}\text { Convention for the } \\
\text { Suppression of Unlawful } \\
\text { Seizure of Aircraft }\end{array}$ & $\begin{array}{l}\text { Dezembro de } \\
1970\end{array}$ & $\begin{array}{l}\text { Março de } \\
1973\end{array}$ & $\begin{array}{l}\text { Fevereiro de 1972 } \\
\text { (Decreto 70201) }\end{array}$ \\
\hline $\begin{array}{l}\text { Convenção para Prevenir e } \\
\text { Punir Atos de Terrorismo } \\
\text { Configurados na Forma de } \\
\text { Delitos Contra as Pessoas e } \\
\text { a Extorsão Conexa, Quando } \\
\text { Tiverem Eles Transcendência } \\
\text { Internacional }\end{array}$ & $\begin{array}{l}\text { Fevereiro de } \\
1971\end{array}$ & $\begin{array}{l}\text { Fevereiro de } \\
1971\end{array}$ & $\begin{array}{l}\text { Abril de 1999 } \\
\text { (Decreto 3018) }\end{array}$ \\
\hline $\begin{array}{l}\text { Convention for the } \\
\text { Suppression of Unlawful Acts } \\
\text { Against the Safety of Civil } \\
\text { Aviation }\end{array}$ & $\begin{array}{l}\text { Setembro de } \\
1971\end{array}$ & Julho de 1975 & $\begin{array}{l}\text { Junho de 1973 } \\
\text { (Decreto 72383) }\end{array}$ \\
\hline $\begin{array}{l}\text { Convention on the Prevention } \\
\text { and Punishment of Crimes } \\
\text { against Internationally } \\
\text { Protected Persons, Including } \\
\text { Diplomatic Agents }\end{array}$ & $\begin{array}{l}\text { Dezembro de } \\
1973\end{array}$ & $\begin{array}{l}\text { Fevereiro de } \\
1977\end{array}$ & $\begin{array}{l}\text { Setembro de 1979 } \\
\text { (Decreto 3167) }\end{array}$ \\
\hline $\begin{array}{l}\text { International Convention } \\
\text { Against the taking of Hostages }\end{array}$ & $\begin{array}{l}\text { Dezembro de } \\
1979\end{array}$ & Junho de 1983 & $\begin{array}{l}\text { Junho de 2000 } \\
\text { (Decreto 3517) - } \\
\text { Com reservas ao } \\
\text { Art. 16. }\end{array}$ \\
\hline $\begin{array}{l}\text { Convention on the Physical } \\
\text { Protection of Nuclear Material }\end{array}$ & $\begin{array}{l}\text { Março de } \\
\text { Agro }\end{array}$ & $\begin{array}{l}\text { Fevereiro de } \\
1987\end{array}$ & $\begin{array}{l}\text { Abril de 1991 } \\
\text { (Decreto 95) }\end{array}$ \\
\hline $\begin{array}{l}\text { Convention for the } \\
\text { Against the Safety of Civil } \\
\text { Aviation }\end{array}$ & $\begin{array}{l}\text { Setembro de } \\
\text { Dezembro de }\end{array}$ & $\begin{array}{l}\text { Junho de 1998 } \\
\text { (Decreto 2611) }\end{array}$ \\
\hline
\end{tabular}




\section{6 | InterAção}

\begin{tabular}{|l|l|l|l|}
\hline $\begin{array}{l}\text { Convention for the } \\
\text { Suppression of Unlawful Acts } \\
\text { Against the Safety of Maritime } \\
\text { Navigation }\end{array}$ & $\begin{array}{l}\text { Março de } \\
1988\end{array}$ & Junho de 1992 & $\begin{array}{l}\text { Não participou } \\
\text { (52 Estados } \\
\text { Ratificaram })^{30}\end{array}$ \\
\hline $\begin{array}{l}\text { Protocol for the Suppression } \\
\text { of Unlawful Acts Against the } \\
\text { Safety of Fixed Platforms } \\
\text { Located on the Continental } \\
\text { Shelf }\end{array}$ & $\begin{array}{l}\text { Março de } \\
1988\end{array}$ & $\begin{array}{l}\text { Março de } \\
1992\end{array}$ & Não participou \\
\hline $\begin{array}{l}\text { Convention on the Marking } \\
\text { of Plastic Explosives for the } \\
\text { Purpose of Detection }\end{array}$ & $\begin{array}{l}\text { Março de } \\
1991\end{array}$ & $\begin{array}{l}\text { Março de } \\
1991\end{array}$ & $\begin{array}{l}\text { Novembro de 2001 } \\
\text { (Decreto 4021) }\end{array}$ \\
\hline $\begin{array}{l}\text { International Convention for } \\
\text { the Suppression of Terrorist } \\
\text { Bombings }\end{array}$ & $\begin{array}{l}\text { Dezembro de } \\
\text { Dog7 }\end{array}$ & Maio de 2001 & $\begin{array}{l}\text { (Decreto 4394) } \\
\text { Com reservas ao } \\
\text { Parágrafo 1 do } \\
\text { Art. 20 }\end{array}$ \\
\hline $\begin{array}{l}\text { International Convention } \\
\text { for the Suppression of the } \\
\text { Financing of Terrorism }\end{array}$ & $\begin{array}{l}\text { Dezembro de } \\
1999\end{array}$ & Abril de 2002 & $\begin{array}{l}\text { Dezembro de 2005 } \\
\text { (Decreto 5640) }\end{array}$ \\
\hline $\begin{array}{l}\text { Inter-American Convention } \\
\text { Against Terrorism }\end{array}$ & Junho de 2002 & Junho de 2002 & $\begin{array}{l}\text { Dezembro de 2005 } \\
\text { (Decreto 5639) }\end{array}$ \\
\hline $\begin{array}{l}\text { International Convention for } \\
\text { the Suppression of Acts of } \\
\text { Nuclear Terrorism }\end{array}$ & $\begin{array}{l}\text { Setembro de } \\
2005\end{array}$ & $\begin{array}{l}\text { Outubro de } \\
\text { 2005 }\end{array}$ & $\begin{array}{l}\text { Não ratificado (em } \\
\text { trâmite } \\
\text { assinado - mas 14 de } \\
\text { Setembro de 2005 }\end{array}$ \\
\hline
\end{tabular}

30 Conforme citado no Seminário "Comunicação e Violência: a opinião pública no combate ao terror", disponível na Internet no endereço http://www.sinprorp.org.br/ Cursos/2001/cursos120.htm, em Dezembro de 2007.

31 Conforme o Sistema de Consultas de Tramitações da Câmara dos Deputados, disponível no endereço http://www2.camara.gov.br/internet/proposicoes/chamadaExterna.html?link=http://www.camara.gov.br/sileg/Prop_Lista. asp?ass $1=$ terrorismo\&c01=\%20AND\%20\&Ass2=nuclear\&c02=Ass3=, acessado em $1^{\circ}$ de fevereiro de 2012. 